Journal of Contemporary Research in Business, Economics and Finance

ISSN: 2641-0265

Vol. 2, No. 2, pp. 37-46

2020

Publisher: Learning Gate

DOI: 10.33094/26410265.2020.22.37.46

(C) 2020 by the authors; licensee Learning Gate

\title{
Dissecting the Linkages between Variations in Crude Oil Price and Selected Macroeconomic Variables in Nigeria
}

\author{
Miriam Kamah \\ School of Economics, Huazhong Univ. of Sci. \& Tech., Wuhan, Hubei, China. \\ Email:kamahmiriam@yahoo.com \\ Joshua S. Riti \\ Department of Economics, University of Jos, Jos Plateau, Nigeria. \\ Email: ritij@unijos.edu.ng
}

Received: 27 August 2020; Revised: 30 September 2020; Accepted: 12 October 2020; Published: 26 October 2020

\begin{abstract}
This study examines the dependency between changes in crude oil price and 15 Nigerian macroeconomic variables. We employ a monthly time series data covering the period from January 2000 to December 2019 and recently refined feasible generalized least square estimator (FGLS) which has the advantage of fixing data problems such as persistency, endogeneity, and heteroscedasticity. The findings of the study shows that oil price changes could substantially predict 10 out of 15 dependent macroeconomic variables, namely all share index, exchange rate, interest rate, inflation, GDP, market capitalization, market capitalization/GDP ratio, net foreign asset, quasi money, and total foreign reserve. 7 out of these 10 significant macroeconomic variables respond to oil price change when the predicting horizon was varied for 4 different periods. However, oil did not substantially predict GDP in the out - of - sample forecast, but did in 3/4 of the in-sample forecast. Also, the null hypothesis of no predictability applies to the remaining 5 macroeconomic variables, namely, money supply 1, money supply 2, net domestic credit, currency in circulation and demand deposit. We recommend the need for consistent monitoring of oil price behavior by regulators so as to counteract its adverse effects by the use of monetary policy and to also intensify the diversification process of other sectors of the economy.
\end{abstract}

Keywords: Crude oil price, GDP, Volatility, Macroeconomic variables, Predictability, FGLS.

\section{Introduction}

Since the 1970s' recession which largely affected the advanced economies was predominantly blamed on crude oil crisis, attention has been drawn to the study of movements in crude oil price and its impact on macroeconomic components. Nevertheless, the discourse on this matter continues due to the contradicting empirical evidences and total macroeconomic consequences of oil price movements on the advanced and developing countries (Morana, 2017). Regardless, a vast number of the studies support the argument that oil price shocks hinder economic growth. For example, Hamilton (1983) and Mork (1989) asserts that movements in oil price can emanate from economic downswings. They further elaborated that changes in oil price influences the production of goods and services from both the supply part and the demand angle of an economy likewise. The supply part effect emanates from the production angle when market supply drops resulting from growing inputs cost (such as oil) which in turn slides the market equilibrium. Although, the demand side effect is connected to purchases and consumption style of economic agents. For example, due to the inelastic nature of the demand for oil, an upward movement in oil price reduces the purchasing power of households. Hence, rising oil prices have immediate effects on consumer goods and services which can lead to future uncertainty. As such, both 
firms and households are coerced into decreasing their investment and consumption spending (Sill, 2007).

Growing oil price negatively affects economic productivity in the short-run, such that it discourages large purchases of both consumer and input goods (Bernanke, 1983). However, rising oil prices not just slowdown economic performance, it also leads to the growth of inflation in the economy. Given that crude oil is commonly utilized as a factor input in manufacturing and also, in the dissemination of goods and services. To this regards, growing oil prices positively influences production cost and inversely affect the cost of distributing goods and services. In addition, changes in oil price directly impacts exchange rate movements. But, the status of the country as net exporter or importer determines the pattern of the movement (Ahmed, Bhutto, \& Kalhoro, 2019; Amano \& Van Norden, 1998; Hamilton, 1996; Issa, Lafrance, \& Murray, 2008; Richard \& Michael, 1980). The purchasing power parity (PPP) theory asserts that a growth in the demand for a country's currency will cause its value to appreciate. Consequently, high oil prices could lead to an appreciation in the worth of the currency of a country that exports oil since it raises the demand for the currency in the foreign exchange market. On the contrary, rising oil prices make the worth of the currency of an oil-importing country to depreciate because it raises the currency's supply in the global market (Ahmed et al., 2019).

The consequences of oil price volatility on an economy's productivity and overall price level is adverse, as a result of that central banks are thus confronted with the challenges of creating policies to stabilize price level and output, concurrently. A common approach adopted by most central banks is to try to keep the growth rate of output by decreasing interest rate to counteract the losses in the real gross domestic product (GDP), although, this could have upward inflationary effects. On the other hand, regulators may also react to the external supply pressure by adopting a pliable inflation targeting policy thereby increasing the interest rate to hinder the adverse effect on the productivity (Bernanke., Gertler, Watson, Sims, \& Friedman, 1997). Nevertheless, some studies emphasize that the response of monetary authorities can possibly clear-up the influence of oil price shocks on an economy (Clarida, Gali, \& Gertler, 2000; Shahbaz, Naeem, Ahad, \& Tahir, 2018; Tatom, 1988).

Nigeria is a major exporter and importer of petroleum oil and products. Nigeria ranks the highest oil producing country in Africa. She is also among the world's top 10 oil producer and also a member of the organization of oil producing countries (Twin, 2019). Nigeria also widely imports processed petroleum products due to its limited number of refineries. According to the statistics of the world trade organization report in world Integrated trade solution, World Integrated Trade Solution WITS (2019)

petroleum oils and products occupies the topmost positon in both export and import trade statistics of Nigeria. Over the years, fluctuations in oil prices impacted adversely on the Nigerian economy as seen during the recession that followed the global financial crisis of 2009 (Sanusi, 2012). Again, in 2016 the Nigerian economy was thrown into another recession which was largely attributed to the fall in the global crude price. Being a country that is largely dependent on crude oil production, how do the variations in crude oil price affect economic performance in Nigeria? This study intends to examine the extent to which oil price is capable of predicting some selected macroeconomic variables in Nigeria. This paper contributes the first logical analysis of the relationship between oil and 15 other macroeconomic variables using the newly advanced FGLS. The study contributes to the existing literature by including more variables to the study. The paper's primary contribution is finding that oil determines 10 out of 15 independent variables.

Subsequently, section two is the literature review and section three briefs about the methodology. The empirical findings will be discussed in section four and section five houses the conclusion and policy implication.

\section{Review of Related Literature}

This section centers on the examination of studies that relates to crude oil price movements and economic performance. Changes in oil price influences the performance of an economic in diverse ways: From the classical economists' point of view, the supply side consequence of a growth in oil price is that 
it raises production cost, which in turn slows down the expansion of goods and services. This means that rising oil price affects the trade of countries that import oil negatively and on the other hand, the oil exporting countries will have more income. Another effect of an increase in oil price can be seen from the angle of money demand. The growth in oil price can also raise the amount of money demanded. If there is no sound counter reaction by the monetary authorities to this growth, the rate of inflation may shift upward, there could be decline in investments, and the ultimate outcome would be a decline in the gross domestic product (GDP). Even though the nominal wages may increase, consequent of the upsurge in inflation the real wages reduces, this results in the price-wage web in an economy. In addition, oil price movements may influence the factors of production and in turn have negative consequences on unemployment in the short run, but in the long run oil price increases could trigger structural changes for the energy sectors (Abeysinghe, 2001; Cunado \& DeGracia, 2005; Lardic \& Mignon, 2008). Cheung and $\mathrm{Ng}$ (1998) evaluate the long run interrelationship among stock market indices of some advanced countries and the determinants of the overall real economy performance using the Johanson co-integration test. Their evidence shows that oil price relates and stock prices move in opposite direction. Eryiğit (2012) using the vector autoregression (VAR) examines the independence between oil price movements and some macroeconomic variables in Turkey. The result indicates that exchange rate, interest rate and stock market returns are related to oil price shocks. Rautava (2004) analyses the influence of global oil prices and real exchange rate on the Russian's fiscal policy and economy using the vector autoregressive model and co-integration method. The result suggests that movements in the Russian real exchange rate and economy, are mainly influenced by oil price. Papapetrou (2001) asserts that oil price movements have negative impact on Greece industrial production and employment. Again, Sharma, Phan, and Iyke (2019) analyze the influence of oil price fluctuation on 31 macroeconomic variables in Indonesia by applying the generalized least squares estimators. The outcome of their study shows that movements in oil price determines 8 of the 31 variables studied. Phoong and Phoong (2019) evaluate the relationship between oil price and macroeconomic variables of the Malaysian economy based on the autoregressive distributed lag (ARDL) technique. The outcome shows a positive relationship between shocks in oil price and inflation as well as economic growth, while unemployment responded negatively to oil price shocks. Abdulkareem and Abdulhakeem (2016) examine the oil price and macroeconomic volatility in Nigeria using the generalized autoregressive conditional heteroscedasticity $(\mathrm{GARCH})$ models. The outcome shows that oil price changes influences volatility of macroeconomic variables in Nigeria. While their study focuses on the asymmetric relation between each of the variables and oil price volatility. Apparently from the literature reviewed, there exist some magnitude of interrelationship between oil price change and macroeconomic variables. But, some studies proved otherwise such as, Jawad and Niazi (2017) using the VAR approach asserted that the fluctuations in macroeconomic variables is caused by the shock from the variable itself rather than shocks from the oil price changes in the case of Pakistan economy. Again, Iwayemi and Fowowe (2011) using the VAR approach asserts that movements in oil price do not have substantial influence on macroeconomic variables in Nigeria. This brings us to the point that the discourse on the crude oil price - macroeconomic variable relationship needs more study in terms of methodology and more variable need to be exploited. On the whole, a significant number of literature suggests that oil price changes substantially impacts the behavior of macroeconomic variables. There is the possibility that it could also have some significantly influence on other total demand and aggregate supply elements of the economy. This study contributes to literature by examining both impact of oil price changes to both the supply and demand components of an oil export dependent economy which also doubles as a large importer of refined crude oil/products.

\section{Data and Methodology}

Following Sharma et al. (2019) we use monthly data of 16 macroeconomic indicators for Nigeria, spanning from January, 2000 to December, 2019. We computed the percentage change in GDP growth rate $(\mathrm{GDP})$, interest rate (ITR), inflation rate (IFL), exchange rate (EXC), all share index (ASI), crude 
oil price (OIL), market capitalization (CAP), market capitalization percentage of GDP (C_GDP), total foreign reserve (TFR) narrow money supply (M1), net foreign asset (Net_FA), net domestic credit (Net_DC), currency in circulation (CIC), broad money supply (M2), quasi money supply (QM), and demand deposit (DD). The period under study spans from January 2000 to December 2019 and the number of observations ranges from 180 to 240 depending on the availability of data. The start and end dates of the data and the acronym can be found at the appendix. The data are gotten from the central bank of Nigeria (CBN), and the Nigerian stock exchange (NSE).

To understand the sensitivity of macroeconomic variables to crude oil price volatility Nigeria, we follow Sharma et al. (2019) by adopting the feasible generalized least squares (FGLS) estimator advanced by Westerlund and Narayan (2012); Westerlund and Narayan (2015). The null hypothesis is that crude oil price changes do not predict 15 macroeconomic variables in Nigeria. We claim that oil price changes can predict these variables as defined by the FGLS model in Equation 1. The FGLS is a predictive regression model defined as.

$$
y_{t}=\alpha_{i}+\beta x_{t-1}+\varepsilon_{t}
$$

Where, $y$ represents any of the economic variables and $\mathrm{x}$ represents crude oil price, $\alpha$ and $\beta$ are parameters, $\varepsilon$ is the disturbance term and $t$ is the time variable. To ascertain our claim, Equation 1 defines the relationship between the dependent variable at time $\mathrm{t}\left(y_{t}\right)$ and the independent or predictor variable at a time lag $\left(x_{t-1}\right)$. In our case, change in oil price is the predictor variable while, the other 15 variables are the outcome variables. Therefore, we estimate the above predictive model sequentially for each of the 15 macroeconomic variables respectively. The choice of using the FGLS is in its ability to address the issue of persistence, serial correlation and heteroscedasticity in the data. The Westerlund and Narayan (2012); Westerlund and Narayan (2015) approach gives room the concurrent modeling of the persistency and endogeneity of the exogenous variable and also handles heteroscedastic issues in a series.

\section{Results Presentation and Discussion of Findings}

In this section we discuss the results obtained from the data estimation. Table 1, presents the summary statistics of all variables under consideration.

Table-1.

Descriptive Statistics.

\begin{tabular}{ccccccccc}
\hline Variable & Mean & SD & Skew. & Kur. & JB & AR(1) & ADF(5) & ARCH-LM (12) \\
\hline OIL & 0.374 & 8.452 & -0.961 & 5.408 & $94.92^{*}$ & 0.902 & $-6.20^{*}$ & $28.98^{*}$ \\
ASI & 0.691 & 7.26 & -0.305 & 7.638 & $218.9^{*}$ & 0.539 & $-4.89^{*}$ & $46.35^{*}$ \\
EXC & 0.447 & 2.729 & 4.173 & 37.52 & $12615^{*}$ & 0.646 & $-5.71^{*}$ & $48.74^{*}$ \\
ITR & -0.135 & 1.366 & 0.429 & 6.891 & $274.2^{*}$ & -0.142 & $-3.1^{* * *}$ & $33.99^{*}$ \\
IFL & 0.301 & 6.446 & -0.115 & 8.166 & $90.99^{*}$ & 0.539 & $-4.722^{*}$ & $26.34^{*}$ \\
GDP & 0.174 & 0.831 & 0.211 & 2.646 & $74.32^{*}$ & 0.577 & $-4.498^{*}$ & $27.06^{*}$ \\
M1 & 1.207 & 5.760 & 0.758 & 6.545 & $111.5^{*}$ & -0.154 & $-5.143^{*}$ & $22.77^{*}$ \\
NET_FA & 1.071 & 6.911 & 0.411 & 5.625 & $56.75^{*}$ & -0.047 & $-4.016^{*}$ & $18.32^{* * *}$ \\
NET_DC & 1.528 & 12.76 & 0.630 & 18.63 & $1845^{*}$ & -0.149 & $-4.404^{*}$ & $44.17^{*}$ \\
CIC & 0.841 & 5.529 & 0.441 & 4.216 & $16.92^{*}$ & -0.245 & $-7.365^{*}$ & $94.10^{*}$ \\
M2 & 1.405 & 5.112 & 1.413 & 25.49 & $3855^{*}$ & -0.195 & $-5.700^{*}$ & $36.95^{*}$ \\
QM & 1.595 & 6.678 & 1.791 & 36.13 & $8326^{*}$ & -0.546 & $-5.99^{*}$ & $33.71^{*}$ \\
DD & 1.307 & 7.372 & 0.742 & 12.09 & $636.8^{*}$ & -0.204 & $-5.52^{*}$ & $39.26^{*}$ \\
TFR & 1.032 & 6.612 & 0.444 & 5.060 & $37.73^{*}$ & 0.022 & $-4.28^{*}$ & $27.41^{*}$ \\
CAP & 1.216 & 5.689 & 1.513 & 11.60 & $1465.4^{*}$ & 0.615 & $-4.15^{*}$ & $36.72^{*}$ \\
C_GDP & 0.115 & 6.150 & 0.548 & 12.76 & $1674.9^{*}$ & 0.667 & $-6.51^{*}$ & $83.95^{*}$ \\
\hline NEt SD & &
\end{tabular}

Note: SD refers to standard deviation, skew refers to skewness, kur refers to kurtosis, and JB refers to Jarque-Bera test. Augmented Dickey-Fuller (ADF) and the ARCH-LM test is the Langrange Multiplier autoregressive conditional heteroscedasticity test. Values marked as *,** and **** symbolizes the of $1 \%, 5 \%$ and $10 \%$ level of significance respectively. 
Based on the results of the summary statistics as shown in Table 1, quasi money (QM) has the highest value of percentage average change (1.60\%), next is the change in the net domestic credit (Net_DC), whereas only the change in interest rate has a negative average value. The net domestic credit has the largest value of standard deviation (12.76\%), next to it, is the change in crude oil price (8.45\%). OIL, ASI and IFL are negatively skewed while the remainder of the variables skewed positively. The variables are not normally distributed, they all have kurtosis value that is greater than 3 , and this is also supported by the outcome of the Jarque-Bera statistic which has probability value of less than $5 \%$ for the series. The coefficients of the autoregressive model (AR1), is significant for most of the series, this implies persistence. The persistence of a variable can be examined by the coefficient of the AR model which is anticipated to be near unity (see, Sharma et al. (2019)). The predictor variable (OIL) is strongly persistent with an AR coefficient close to 1 . Other variables that are persistent in the series, have AR coefficients of greater than 0.5, this include ASI, IFL, GDP, CAP, C_CAP, QM and EXC. This implies that majority of the series are less persistent. The Augmented Dickey-Fuller statistic shows that each of the series under consideration is stationary, while the autoregressive conditional heteroscedasticity (ARCH-LM) test have significant coefficients indicating the presence of non-constant variance for each of the series. Next we examine whether crude oil is an endogenous variable by regressing the error term from the Equation 1 on the residual from the AR process of OIL and the result is documented in Table 2 . Table 2 presents the outcome of the endogeneity test and based on the finding from this test, we fail to accept the null hypothesis that the coefficient of the slope is zero for ASI, IFL, NET_FA and CAP. This implies that oil price is endogenous to 4 of the macroeconomic variables. There is the possibility of a cause-effect dependence between some of the macroeconomic variable and oil price. Most of the variables turned out to be insignificant, but probably because Nigeria is a small open economy as such, its economy might not have large effect on the world oil price. Based on the results discussion so far, the usage of the FGLS model is justified, because we need to account for the issues of persistence and endogeneity which exist in the series under consideration.

Table-2.

The endogeneity test result.

\begin{tabular}{ccc}
\hline Variable & Coefficient & p-value \\
\hline ASI & $0.047^{*}$ & 0.018 \\
EXC & 0.136 & 0.491 \\
ITR & 0.306 & 0.257 \\
IFL & $0.113^{*}$ & 0.049 \\
GDP & 0.046 & 0.956 \\
CAP & $0.032^{*}$ & 0.035 \\
C_GDP & 0.227 & 0.639 \\
M1 & 0.103 & 0.744 \\
NET_FA & $0.004^{*}$ & 0.049 \\
NET_DC & 0.145 & 0.235 \\
CIC & 0.016 & 0.139 \\
M2 & 0.345 & 0.622 \\
QM & 0.09 & 0.153 \\
DD & 0.117 & 0.528 \\
TFR & 0.001 & 0.103 \\
\hline
\end{tabular}

Note: The endogeneity test is based on the residuals from the first-order autoregressive predictor regression model. The equation is: $\varepsilon_{t}=m \tau_{t}+\mu_{t}$; where $\varepsilon_{t}$ is the residual from the predictive regression model and $\tau_{t}$ is the residual from the $\operatorname{AR}(1)$ regression of the predictor. We reject the null hypothesis that the slope coefficient $(\boldsymbol{m})$ is zero for some variables. This implies the existence of endogeneity in the predictive regression model. * symbolizes $5 \%$ level of statistical significance. 
Table-3.

The FGLS in-sample predictability outcome.

\begin{tabular}{ccc}
\hline Variable & Coefficient & p-value \\
\hline ASI & $0.212^{*}$ & 0.000 \\
EXC & $-0.015^{*}$ & 0.004 \\
ITR & $0.130^{*}$ & 0.012 \\
IFL & $0.014^{* *}$ & 0.059 \\
GDP & 0.173 & 0.089 \\
CAP & $0.032^{* *}$ & 0.047 \\
C_GDP & $0.021^{* * *}$ & 0.074 \\
M1 & 0.161 & 0.695 \\
NET_FA & $0.117^{* *}$ & 0.046 \\
NET_DC & 0.025 & 0.819 \\
CIC & 0.015 & 0.746 \\
M2 & -0.056 & 0.198 \\
QM & $-0.082^{* *}$ & 0.046 \\
DD & -0.0291 & 0.169 \\
TFR & $1.022^{* *}$ & 0.040 \\
\hline
\end{tabular}

Note: Values marked as $*^{*},{ }^{*}$ and $* * *$ denotes significant at $1 \%, 5 \%$ and $<10 \%$, level of significance respectively.

Table 3 reports, the estimates of the in-sample predictability test outcomes of the bias-adjusted FGLS estimator advanced by Westerlund and Narayan (2012); Westerlund and Narayan (2015). In particular, we state that the in-sample WN-FGLS coefficient and the resultant p-value for one month ahead $(h=1)$ of the macroeconomic variables respectively.

Our outcome signals that oil price is capable of predicting 10 macroeconomic elements of the Nigerian economy. These are; ASI, EXC, ITR, IFL, GDP, CAP, C_GDP, NET_FA, QM and TFR. The 8 out of the 10 significant variables have positive sign. This supports the argument that the Nigerian economy relies heavily on crude oil export, as such increases in oil prices positively affects economic variable, while, EXC and QM have negative sign. EXC is negative because Nigeria is an oil exporter, as such oil price increases appreciates the naira (domestic currency). The null hypothesis of no predictability applies to the remaining 5 macroeconomic indicators. These are; M1, M2, NET_DC, CIC and DD.

Furthermore, we performed an in-sample predictability tests by varying 3 forecasting horizons: two months $(h=2)$, three months $(h=3)$, and six months $(h=6)$. The estimates from the WN-FGLS and their resultant probability values for the various 3 predictive ranges can be seen in Table 4. Here, outcome shows that oil price substantially predicts 7 macroeconomic elements (ASI, EXC, ITR, IFL, CAP, NET_FA and TFR) regardless of the forecasting horizons employed and that the sign of the predictor stays almost fixed no matter the forecasting horizons employed.

It is notable that 2 out of the variables under study, GDP and QM were influenced by oil price is a substantial predictor in 3 out of the 4 forecasting horizons considered. In sum, based on the findings from the in-sample predictability tests, the outcome suggests that the null hypothesis of no predictability applies to 5 macroeconomic variables cannot be discarded.

Table 5 , shows the out-of-sample forecasting evaluation. The out-of-sample forecast analysis shows the relevance of oil price in explaining the macroeconomic elements against the constant-only model (benchmark model). We examine $70 \%$ in-sample period to create repeated predictions of the variable in about $30 \%$ of the sample left. In order to collate the projecting efficiency of the oil price predictor-based predictive model with the constant-only model, we employ two popular forecasting test of accuracy, specifically, the relative Theil U (RTU) and Campbell and Thompson, 2008 out-of-sample $R^{2}$ (OOR) statistics in finance. 
Table-4.

The result of the in-sample predictability at 3 different predictive length.

\begin{tabular}{|c|c|c|c|c|c|c|}
\hline Variable & $\frac{\mathrm{h}=3}{\text { Coefficient }}$ & p-value & $\frac{\mathrm{h}=3}{\text { Coefficient }}$ & p-value & $\frac{\mathrm{h}=6}{\text { Coefficient }}$ & p-value \\
\hline ASI & $0.194^{*}$ & 0.000 & 0.211 & $0.005^{*}$ & $0.215^{* *}$ & 0.035 \\
\hline $\mathrm{EXC}$ & $-0.018^{*} *$ & 0.017 & $-0.023^{* *}$ & 0.048 & $0.028^{*}$ & 0.036 \\
\hline ITR & $0.125^{* *}$ & 0.019 & $-0.118^{* *}$ & 0.051 & $-0.131^{*}$ & 0.011 \\
\hline IFL & $0.021 * *$ & 0.047 & $0.015^{* * *}$ & 0.020 & $0.019^{*}$ & 0.010 \\
\hline GDP & O. $136^{* * * *}$ & 0.078 & O. $154^{* * * *}$ & 0.095 & -0.152 & 0.174 \\
\hline CAP & $-0.036^{* *}$ & 0.024 & $-0.034 * *$ & 0.553 & -0.037 ** & 0.025 \\
\hline C_GDP & 0.019 & 0.726 & 0.026 & 0.214 & 0.019 & 0.575 \\
\hline M1 & 0.163 & 0.761 & 0.156 & 0.687 & 0.160 & 0.819 \\
\hline NET_FA & O.119* & 0.007 & O.113* & 0.000 & $0.117 * *$ & 0.038 \\
\hline NET_DC & 0.016 & 0.866 & 0.031 & 0.943 & 0.024 & 0.890 \\
\hline $\mathrm{CIC}$ & 0.019 & 0.450 & 0.014 & 0.623 & 0.017 & 0.760 \\
\hline $\mathrm{M} 2$ & -0.048 & 0.553 & -0.059 & 0.715 & -0.068 & 0.660 \\
\hline $\mathrm{QM}$ & -0.016 & 0.125 & -0.039*** & 0.095 & $0.043^{*} * *$ & 0.084 \\
\hline $\mathrm{DD}$ & -0.024 & 0.363 & -0.084 & 0.472 & -0.073 & 0.916 \\
\hline TFR & $0.936^{* *}$ & 0.057 & $0.822^{*} *$ & 0.043 & $0.916^{* * * *}$ & 0.065 \\
\hline
\end{tabular}

Note: Values marked as *, ** and $* * *$ symbolizes significant at $1 \%, 5 \%$ and $10 \%$, level of significance respectively.

Table-5.

The out - of - sample evaluation outcome.

\begin{tabular}{llll}
\hline Variable & RTU & OOR & p-value \\
\hline ASI & 1.012 & -0.007 & 0.151 \\
EXC & 0.915 & $0.068^{*}$ & 0.004 \\
ITR & 0.642 & $0.014^{* *}$ & 0.012 \\
IFL & 0.904 & $0.036^{* *}$ & 0.059 \\
GDP & 1.003 & -0.123 & 0.721 \\
CAP & 1.032 & -0.174 & 0.587 \\
C_GDP & 1.021 & -0.058 & 0.474 \\
M1 & 1.008 & -0.023 & 0.695 \\
NET_FA & 0.897 & $0.043^{*} * *$ & 0.063 \\
NET_DC & 1.025 & -0.153 & 0.819 \\
CIC & 1.001 & -0.097 & 0.746 \\
M2 & 0.456 & $0.046^{*} * *$ & 0.098 \\
QM & 0.782 & $0.013^{*} * *$ & 0.068 \\
DD & 0.816 & $0.005^{* * *}$ & 0.069 \\
TFR & 0.622 & $0.028^{*} *$ & 0.040 \\
\hline Note: Values marked as ${ }^{*}, * *$ and ${ }^{* * *}$ & symbolizes level of significance at $1 \%, 5 \%$ and $10 \%$,
\end{tabular}

respectively.

The RTU is a relative accuracy metric that compares the predicted outcome with the outcome of forecasting with least historical data. Thus, if RTU $=1$, it means that the oil price predictor-based and constant-only models are both identically good at forecasting the variables. But if RTU > 1, it means that the constant-only model surpasses the oil price predictor-based model and vice versa. An OOR assesses the spread in the mean squared errors of the oil price-based predictive model and the constant model. Therefore, by composition, if OOR $>0$, it is regarded that the oil price predictor-based forecasting model outperforms the constant-only model. Additionally, we examine the null hypothesis that OOR $\leq 0$ with the alternative hypothesis that OOR $>0$ using the Clark and West, 2007 MSFEadjusted statistic (Sharma et al., 2019). 
Table 5 contains the outcome of the out-of-sample forecast estimates of the macroeconomic variables forecast length of 1 month ahead. The outcome shows RTU of less than 1, only for these 8 macroeconomic variables. These includes: EXC, ITR, IFL, NET_FA M2, QM, DD and TFR. This implies that the oil price-based predictability model surpasses the constant-only model for these 8 macroeconomic variables only. For the other 7 macroeconomic variables, it is notable that the constantonly model surpasses the oil-price predictor-based predictability model. The OOR statistic yields similar results as the RTU statistic for the same 8 macroeconomic variables with OOR $>0$. This implies that the oil price predictor model outperforms the constant-only model for EXC, ITR, IFL, NET_FA M2, QM, DD and TFR. While the constant-only model is superior to the oil price predictor model for the remaining variables.

Table 6 reports the RTU and OOR statistics for 3 varied projecting horizons $(\mathrm{h}=2, \mathrm{~h}=3$, and $\mathrm{h}=$ 6 ). The outcomes are quite identical for both RTU and OOR statistics. They both give virtually stable outcome regardless of the predicting horizons. Specifically, for $7 / 15$ of the macroeconomic variables, namely EXC, ITR, INF, NET_FA, M2, QM, DD and TFR, the oil price predictor-based model surpasses the constant-only model regardless of the out-of- sample test statistic or the projecting length employed.

Table-6.

The estimates of the out-of-sample predictability with various forecasting length.

\begin{tabular}{lllllll}
\hline Variable & $\underline{\mathbf{h}=\mathbf{3}}$ & & $\underline{\mathbf{h}=\mathbf{3}}$ & $\mathbf{O O R}$ & $\underline{\mathbf{h}=6}$ & \\
& $\mathbf{R T U}$ & OOR & $\underline{\mathbf{R T U}}$ & & $\mathbf{R T U}$ & OOR \\
\hline ASI & 1.082 & 0.000 & 1.103 & -0.015 & 1.005 & -0.065 \\
EXC & 0.864 & 0.040 & 0.891 & 0.034 & 0.885 & 0.036 \\
ITR & 0.625 & 0.019 & 0.620 & 0.006 & 0.623 & 0.023 \\
IFL & 0.913 & 0.047 & 0.915 & 0.048 & 0.920 & 0.010 \\
GDP & 1.006 & -0.109 & 1.014 & -0.104 & 1.008 & -0.101 \\
CAP & 1.033 & -0.124 & 1.038 & -0.118 & 1.030 & -0.125 \\
C_GDP & 1.016 & -0.066 & 1.007 & -0.086 & 1.004 & -0.075 \\
M1 & 1.009 & -0.061 & 1.016 & -0.051 & 1.020 & -0.051 \\
NET_FA & 0.883 & 0.087 & 0.886 & 0.007 & 0.882 & 0.008 \\
NET_DC & 1.002 & -0.166 & 1.003 & -0.104 & 1.043 & -0.107 \\
CIC & 1.032 & -0.050 & 1.059 & 0.000 & 1.028 & -0.060 \\
M2 & 0.548 & 0.053 & 0.553 & 0.068 & 0.557 & 0.060 \\
QM & 0.614 & 0.015 & 0.639 & 0.043 & 0.635 & 0.024 \\
DD & 0.824 & 0.063 & 0.827 & 0.073 & 0.832 & 0.016 \\
TFR & 0.636 & 0.027 & 0.622 & 0.031 & 0.619 & 0.033 \\
\hline Note: Values marked as* ** and *** symbolizes a $\%, 5 \%$ and $10 \%$, level of significance respectively. &
\end{tabular}

In summary, based on the result from this study, in both the in-sample and out-of-sample predictability analyses, oil price changes substantially predicts 10 out of the 15 macroeconomic variables (ASI, EXC, ITR, IFL, GDP, CAP, C_GDP, NET_FA, QM and TFR) studied. The ability of oil price to predict EXC in our case study as contrary to Sharma et al. (2019), can be attributed to the fact that oil is the main foreign exchange earner in Nigeria, as such it determines what happens in the foreign exchange market. This is due to the neglect of other sectors of the economy and relying mostly on crude oil export. However, oil did not substantially predict GDP in the out - of - sample forecast, but did in $3 / 4$ of the in-sample forecast. This implies the possibility of the action of the monetary authorities to clear up the effects of oil price rise on GDP. Overall, our findings are similar to Sharma et al. (2019); Ahmed et al. (2019); Shahbaz et al. (2018); Papapetrou (2001) and Rautava (2004). 


\section{Conclusion and Policy Recommendations}

This study analyzes 16 monthly variables of the Nigerian economy from year 2000 to 2019. We precisely analyzed the ability of oil price to predictor of 15 other macroeconomic variables by employing the WNFGLS in-sample in this study, we resolve data related problems such as persistency, heteroscedasticity, and endogeneity simultaneously. Precisely, we examine the predictability tests at 4 various projecting time length of the oil price-predictor model. The predicting time length $(\mathrm{h})$ are: one month, two months, three months, and six months ahead forecasts for both the in-sample and out-ofsample examinations. Our findings suggests that oil price movements is pivotal to Nigerian economic performance, since it determines 8 out of the 15 dependent variables. This implies that oil price changes is significant in sharpening monetary policy instruments in Nigeria as seen from the results. 2 monetary policy indices (INF and ITR) where significant throughout the study. This study recommends that the CBN should pay keen attention to oil price fluctuations in the formulation of its policies.

\section{References}

Abdulkareem, A., \& Abdulhakeem, K. A. (2016). Analysing oil price-macroeconomic volatility in Nigeria. CBN Journal of Applied Statistics, 7(1), 1-22.

Abeysinghe, T. (2001). Estimation of direct and indirect impact of oil price on growth. Economics Letters, 73(2), 147-153. Available at: https://doi.org/10.1016/s0165-1765(01)00476-1.

Ahmed, K., Bhutto, N. A., \& Kalhoro, M. R. (2019). Decomposing the links between oil price shocks and macroeconomic indicators: Evidence from SAARC region. Resources Policy, 61, 423-432. Available at: https://doi.org/10.1016/j.resourpol.2018.03.001.

Amano, R. A., \& Van Norden, S. (1998). Oil prices and the rise and fall of the US real exchange rate. Journal of International Money and FFinance, 17(2), 299-316. Available at: https://doi.org/10.1016/s0261-5606(98)00004-7.

Bernanke, B. S. (1983). Non-monetary effects of the financial crisis in the propagation of the Great Depression: National Bureau of Economic Research Cambridge, Mass, USA.

Bernanke., B. S., Gertler, M., Watson, M., Sims, C. A., \& Friedman, B. M. (1997). Systematic monetary policy and the effects of oil price shocks. Brookings Papers on Economic Activity, 1997(1), 91-157. Available at: https://doi.org/10.2307/2534702.

Cheung, Y.-W., \& Ng, L. K. (1998). International evidence on the stock market and aggregate economic activity. Journal of Empirical Finance, 5(3), 281-296. Available at: https://doi.org/10.1016/s0927-5398(97)00025-x.

Clarida, R., Gali, J., \& Gertler, M. (2000). Monetary policy rules and macroeconomic stability: Evidence and some theory. The Quarterly Journal of Economics, 115(1), 147-180. Available at: https://doi.org/10.1257/aer.100.1.491.

Cunado, J., \& DeGracia, F. P. (2005). Oil prices, economic activity and inflation: Evidence for some Asian countries. The Quarterly Review of Economics and Finance, 45(1), 65-83. Available at: https://doi.org/10.1016/j.qref.2004.02.003.

Eryiğit, M. (2012). The dynamical relationship between oil price shocks and selected macroeconomic variables in Turkey. Economic Research-Ekonomska istraživanja, 25(2), 263-276. Available at: 10.1080/1331677X.2012.11517507.

Hamilton, J. D. (1983). Oil and the macroeconomy since World War II. Journal of Political Economy, 91(2), 228-248. Available at: https://doi.org/10.1086/261140.

Hamilton, J. D. (1996). This is what happened to the oil price-macroeconomy relationship. Journal of Monetary Economics, 38(2), 215-220. Available at: https://doi.org/10.1016/s0304-3932(96)01282-2.

Issa, R., Lafrance, R., \& Murray, J. (2008). The turning black tide: Energy prices and the Canadian dollar. Canadian Journal of Economics/Revue canadienne d'économique, 41(3), 737-759. Available at: https://doi.org/10.1111/j.15405982.2008.00483.x.

Iwayemi, A., \& Fowowe, B. (2011). Impact of oil price shocks on selected macroeconomic variables in Nigeria. Energy Policy, 39(2), 603-612. Available at: https://doi.org/10.1016/j.enpol.2010.10.033.

Jawad, M., \& Niazi, G. S. K. (2017). Impact of oil price volatility and macroeconomic variables on economic growth of Pakistan. Review of Innovation and Competitiveness: A Journal of Economic and Social Research, 3(1), 49-74. Available at: https://doi.org/10.32728/ric.2017.31/3.

Lardic, S., \& Mignon, V. (2008). Oil prices and economic activity: An asymmetric cointegration approach. Energy Economics, 30(3), 847-855. Available at: https://doi.org/10.1016/j.eneco.2006.10.010.

Morana, C. (2017). Macroeconomic and financial effects of oil price shocks: Evidence for the euro area. Economic Modelling, 64, 82-96. Available at: 10.1016/j.econmod.2017.03.016.

Mork, K. A. (1989). Oil and the macroeconomy when prices go up and down: an extension of Hamilton's results. Journal of Political Economy, 97(3), 740-744. Available at: https://doi.org/10.1086/261625.

Papapetrou, E. (2001). Oil price shocks, stock market, economic activity and employment in Greece. Energy Economics, 23(5), 511-532. Available at: https://doi.org/10.1016/s0140-9883(01)O0078-0. 
Phoong, S. W., \& Phoong, S. Y. (2019). An ARDL approach on crude oil price and macroeconomic variables. Journal of Business and Economics Review, 4(1), 68-73.

Rautava, J. (2004). The role of oil prices and the real exchange rate in Russia's economy - a cointegration approach. Journal of Comparative Economics, 32(2), 315-327. Available at: https://doi.org/10.1016/j.jce.2004.02.006.

Richard, J. C., \& Michael, F. (1980). Oil imports and inflation: An empirical international analysis of the 'imported'inflation thesis. Kyklos, 33(4), 615-622. Available at: https://doi.org/10.1111/j.1467-6435.1980.tboo716.x.

Sanusi, S. L. (2012). Global financial meltdown and the reforms in the Nigerian Banking sector. CBN Journal of Applied Statistics, 2(1), 93-108.

Shahbaz, M., Naeem, M., Ahad, M., \& Tahir, I. (2018). Is natural resource abundance a stimulus for financial development in the USA? Resources Policy, 55, 223-232. Available at: https://doi.org/10.1016/j.resourpol.2017.12.006.

Sharma, S. S., Phan, D. H. B., \& Iyke, B. (2019). Do oil prices predict Indonesian macroeconomy? Economic Modelling, 82, 2-12. Available at: https://doi.org/10.1016/j.econmod.2019.08.008.

Sill, K. (2007). The macroeconomics of oil shocks. Federal Reserve Bank of Philadelphia, Business Review, 1(1), 2 1-31.

Tatom, J. A. (1988). Are the macroeconomic effects of oil-price changes symmetric? Paper presented at the Carnegie-Rochester Conference Series on Public Policy.

Twin, A. (2019). World's top 10 oil exporters. Retrieved from: https://www.investopedia.com/articles/companyinsights/082316/.

Westerlund, J., \& Narayan, P. (2015). Testing for predictability in conditionally heteroskedastic stock returns. Journal of Financial Econometrics, 13(2), 342-375. Available at: https://doi.org/10.1093/jjfinec/nbu001.

Westerlund, J., \& Narayan, P. K. (2012). Does the choice of estimator matter when forecasting returns? Journal of Banking \& Finance, 36(9), 2632-2640. Available at: https://doi.org/10.1016/j.jbankfin.2012.06.005.

World Integrated Trade Solution WITS. (2019). Nigeria trade statitics. Retrieved from: https://wits.worldbank.org/CountryProfile/en/Country/NGA/Year/LTST/Summary.

\section{Appendix A}

Table-1A.

Data names and dates.

\begin{tabular}{llcc}
\hline Acronym & Description & Start-Date & End-Date \\
\hline OIL & \% change in crude oil price & Jan, 2000 & Dec, 2019 \\
ASI & \% change in all share index & Jan, 2000 & Dec, 2019 \\
EXC & \% change in exchange rate & Jan, 2000 & Dec, 2019 \\
ITR & \% change in interest rate & Jan, 2000 & Dec, 2019 \\
IFL & \% change in inflation & Jan, 2000 & Dec, 2019 \\
GDP & \% change in GDP growth rate & Jan, 2000 & Dec, 2019 \\
CAP & \% change in market capitalization & Jan, 2000 & Dec, 2019 \\
C_GDP & \% change in market capitalization-GDP ratio & Jan, 2000 & Dec, 2019 \\
M1 & \% change in money supply 1 & Jan, 2005 & Dec, 2019 \\
NET_FA & \% change in net foreign asset & Jan, 2005 & Dec, 2019 \\
NET_DC & \% change in net domestic credit & Jan, 2005 & Dec, 2019 \\
CIC & \% change in currency in circulation & Jan, 2005 & Dec, 2019 \\
M2 & \% change in money supply 2 & Jan, 2005 & Dec, 2019 \\
QM & \% change in quasi money supply & Jan, 2005 & Dec, 2019 \\
DD & \% change in demand deposit & Jan, 2005 & Dec, 2019 \\
TFR & \% change in total foreign reserve & Jan, 2005 & Dec, 2019 \\
\hline
\end{tabular}

Source: Researchers' compilation.

Journal of Contemporary Research in Business, Economics and Finance
ISSN: $2641-0265$
Vol. 2, No. 2, pp. $37-46,2020$
DOI: $10.33094 / 26410265.2020 .22 .37 .46$
C) 2020 by the authors; licensee Learning Gate

